Ibid., par. 3:

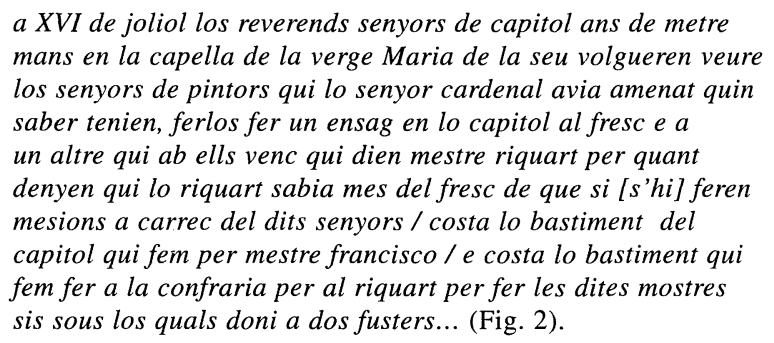

El XVI de julio, los reverendos señores del cabildo, antes de meter mano a la capilla de la Virgen de la Catedral, quisieron conocer de los señores pintores que el Sr. Cardenal había traído qué saber tenían, [y] hacerles hacer un ensayo de la pintura al fresco en la sala capitular, y a otro que con ellos vino, al cual llamaban mestre Riquart, aunque negaban que el Riquart supiese más de fresco, por lo cual se hicieron gastos a cargo de dichos señores. Costó el andamio de la sala capitular que hicimos para mestre Francisco y costó el andamio que hicimos hacer en la cofradía para mestre Riquart, para hacer las dichas muestras, seis sueldos, los cuales entregué a dos carpinteros [...]

Adele Condorelli

\title{
DOS NUEVAS OBRAS DE FRANCISCO GALLARDO
}

La localización de dos lienzos firmados por Francisco Gallardo, uno en Sevilla y otro en Cádiz, amplía las escasas noticias que se conocen sobre la vida y obra de este autor ${ }^{1}$. El cuadro de Cádiz, de propiedad particular, es un trampantojo del tipo conocido como «rincón de taller» y sus dimensiones son $83 \times 62 \mathrm{cms}$. En él destaca una estampa, sobre la que se posa una mosca, clavada al habitual fondo de tablas, y en cuya zona inferior se puede leer: «En Cádiz, año de $1720 \ldots$ Franco. Julo. Gallado F.». Bajo la estampa hay una cinta, sujeta con puntas y atravesada en uno de los extremos por un punzón, que sirve de soporte a una carta plegada en la cual aparece escrito: «Sr. Dn. Franco X...». La obra conservada en Sevilla, también de propiedad particular, mide $157 \times 108 \mathrm{cms}$. y representa a santo Tomás de Aquino. Está firmada: «Franco. Gallardo fecit anno...», aunque en este caso se desconoce la fecha, perdida seguramente en el proceso de reentelado que redujo levemente las dimensiones del lienzo. El momento representado corresponde a una de las visiones místicas del santo, quien, interrumpiendo sus escritos, se arrodilla ante un crucifijo que le dirige las siguientes palabras: «BENE SCRIPSISTI DE ME THOMA». En la zona superior se abre una gloria donde revolotean varios ángeles niños y sobre el pavimento se disponen dos mitras y un capelo, que simbolizan las dignidades eclesiásticas rechazadas ${ }^{2}$.

Estos dos trabajos se suman al reducido catálogo de Francisco Gallardo, compuesto hasta ahora por cuatro trampantojos firmados y fechados en 1764, a los que se puede añadir la atribución de otros cuatro lienzos del mismo género pertenecientes a la colección André Hipola

\footnotetext{
1 Francisco Gallardo fue dado a conocer en la exposición de bodegones y floreros organizada por la Sociedad Española de Amigos del Arte en 1935. Véase Cavestany, J.: Bodegones y floreros en la pintura española, Madrid, 1936-1940, p. 96.

${ }^{2}$ La biografía de Santo Tomás de Aquino recoge varias experiencias místicas de este tipo, en las que Cristo elogia sus escritos. Sobre su repercusión en las creaciones artísticas se ha señalado la existencia de un fresco con este mismo tema en el claustro de Santa María sopra Minerva de Roma. Véase Mâle, E.: El Barroco. El arte religioso del siglo xvII, Madrid, 1985, pp. 409-410.
} 
de Madrid ${ }^{3}$. Pero tan escaso número de piezas resulta suficiente para evidenciar a un interesante especialista en el género del bodegón, cercano al estilo del maestro sevillano Bernardo Germán Lorente, y a un discreto pintor de temas sacros, como nos descubre el Santo Tomás conservado en Sevilla. Más limitados aún son los datos que se conocen sobre su biografía, habiéndose propuesto una posible relación con Cádiz en función de la referencia que se hace a esta ciudad en uno de los lienzos de 1764, vinculación que el trampantojo gaditano parece confirmar ${ }^{4}$.


Figs. 1 y 2. Francisco Gallardo: Trampantojo. Cádiz. Colección particular. Santo Tomás de Aquino. Sevilla. Colección particular.

La composición de este nuevo bodegón fue reutilizada por el pintor en uno de los lienzos madrileños ${ }^{5}$. Frente a lo abigarrado de los trabajos de 1764 , la obra aparece aquí claramente centrada por un único elemento, la estampa, que la ocupa en su mayor parte. Esa estampa reproduce, con algunas variantes, el emblema 93 de la obra de Otto Vaenius (o Van Veen) Quinti Horati Flacci emblemata insignibus in aes nostisque illustrata, al que corresponde el lema: «TUTE, SI RECTE VIXERIS» («SEGURO ESTÁ QUIEN VIVIERE BIEN»), tomado de las Odas de Horacio ${ }^{6}$. El contenido moralizante de la estampa sugiere la intención de realizar un

\footnotetext{
${ }^{3}$ El conjunto de obras autógrafas se conserva en una colección privada de Madrid. Véase Cavestany, J.: ob. cit., pág. 96. Los lienzos atribuidos a Gallardo han sido identificados con los publicados por Torres Martín, pertenecientes a la mencionada colección madrileña, por Pérez Sánchez, A.: Pintura española de bodegones y floreros de 1800 a Goya, Madrid, 1983 , p. 207.

${ }^{4}$ Sobre la obra de Francisco Gallardo, su relación con el círculo de Bernardo Germán Lorente y su posible vinculación a Cádiz puede consultarse Pérez Sánchez, A.: Pintura española de bodegones..., pp. 150-153 y 207, La nature morte espagnole du xvIle. siècle à Goya, Friburgo, 197, pp. 171-174, y Pintura barroca en España (1600-1750), Madrid, 1992, p. 418.
} 
jeroglífico sobre lo implacable e inesperado de la muerte y corrobora el interés que se atribuye a Gallardo por los temas litearios eruditos, puesto de relieve a través de los numerosos libros, dibujos, estampas y cartas que aparecen en sus obras ${ }^{7}$. El éxito de la publicación de Vaenius como fuente de inspiración iconográfica en el arte hispánico del siglo xviII es conocido, destacando su utilización en los paneles de azulejos del claustro del convento de san Francisco en Bahía (Brasil), fechados en 1746-48, y en un biombo mexicano de la segunda mitad del mismo siglo ${ }^{8}$. En Sevilla era también utilizada, como indica el hecho de que esa obra figurase en la biblioteca de Bernardo Germán Lorente, inventariada en $1738^{9}$. Partiendo de tales datos no sería extraño que el cuadro de Cádiz formase parte de un conjunto que, por su cronología, constituiría un precedente de las series ya conocidas.

El alto nivel del grupo de trampantojos firmados por este autor se torna en el lienzo de Santo Tomás en una medianía fiel a modelos del siglo anterior y coincidente con la producción de temática religiosa que encontramos en otros pintores contemporáneos del círculo sevillano. La composición, convencional y arcaizante, está tomada de estampas, aunque la introducción de algunos motivos de inspiración murillesca y el brillo del color aportan cierta vitalidad a la escena. Sólo es posible detectar un eco de la calidad que alcanzan sus bodegones en el tratamiento de los elementos inanimados, pero sin dejar de tener en cuenta que la naturaleza muerta situada sobre la mesa responde a modelos del siglo xvII procedentes de estampas.

El dato más valioso que los nuevos cuadros de Gallardo nos aportan, de cara a la necesaria recuperación de su biografía, es la fecha del bodegón. Su realización en 1720 evidencia un dilatado margen cronológico de cuarenta y cuatro años entre esta obra y las madrileñas, lo que, unido a la inclusión de un segundo nombre en la firma ¿Jul(i)o?, puede plantear algunas dudas sobre la autoría común de los lienzos. Pero, teniendo en cuenta que tanto el estilo como la ejecución presentan rasgos comunes muy similiares, las diferencias cronológicas no impiden señalar que se trate de trabajos representativos de fechas más tempranas y tardías de un mismo autor, especializado desde su juventud en el género del trampantojo. No por ello hay que descartar la posibilidad de que nos encontremos ante dos miembros de una misma familia, tal vez padre en hijo. La escasez de datos impide por el momento cualquier certeza, aunque las fuentes documentales han aportado últimamente algunas referencias sobre maestros sevillanos apellidados Gallardo que pueden guardar alguna relación con los orígenes de Francisco ${ }^{10}$.

\footnotetext{
${ }^{5}$ Se trata del n. ${ }^{\circ} 132$ del catálogo de la exposición de 1983-84, en uno de cuyos extremos aparece un esquema compositivo semejante al del lienzo de 1720. Véase Pérez Sánchez, A.: Pintura española de bodegones..., p. 150.

${ }^{6}$ Agradezco a Benito Navarrete la identificación de esta obra.

El texto latino completo de emblema que reproduce el lienzo de Gallardo es el siguiente: «Quin quisque vitet, numquam homini satis/ cautum est in horas. Navita Bosphorum/ Poenus perorrescit: necque ultra/ Caeca timet aliunde fata. $=$ Miles sagittas, celerem fugam/ Parti: catenas Partus, Italum/ Robur, sed improvisa lethi/ Vis, rapuit, rapietque gentes».

7 También habría que tener en cuenta la posibilidad de que esta temática responda al encargo de un cliente. Sobre las referencias literarias de los bodegones de Gallardo véase Pérez Sánchez, A.: La pintura española de bodegones..., p. 207.

${ }^{8}$ En ambos casos se ha utilizado el emplema 93.

Sobre el influjo de Vaenius en el mundo hispánico a través del Theatro Moral de Toda la Philosophia de los Antiguos y Modernos, versión española del original latino publicado en Amberes en 1607, pueden consultarse los trabajos de Sebastián, S.: «Theatro moral de la vida humana de Otto Vaenius. Lectura y significado de los emblemas», Boletín del Instituto Camón Aznar, XIV, Zaragoza, 1983, pp. 7-9, El Barroco Iberoamericano. Mensaje iconográfico, Madrid, 1990, pp. 254259, «La emblemática moral de Vaenius en Iberoamérica», Goya n. ${ }^{\circ} 234$, Madrid, 1993, pp. 322-330 y Emblemática e Historia del Arte, Madrid, 1995, pp. 262-282.

${ }_{9}^{9}$ Quiles García, F.: «En torno a las posibles fuentes utilizadas por Bernardo Germán Lorente en su pinturas: análisis de la biblioteca y la pinacoteca de su propiedad», Atrio n. ${ }^{\circ}$ 7, Sevilla, 1995, pp. 31-43.

${ }^{10}$ Entre los escasos datos que nos pueden acercar a la biografía de Francisco Gallardo podemos citar la actividad en Sevilla de un maestro pintor llamado Manuel Gallardo en cuyo testamento, otorgado en 1709, declara ser padre de Francisco Gallardo, si bien no especifica su profesión. También se conocen algunos datos sobre un maestro dorador y batihojas llamado Antonio Gallardo, que trabaja en Sevilla entre 1700 y 1708. Véase Quiles García, F.: Fuentes para la Historia del Arte Andaluz. Noticias de pintura (1700-1720), Sevilla, 1990, pp. 87-91.
} 
Son muchas las dudas que aún se plantean al abordar el estudio de Francisco Gallardo, pero la calidad de su obra nos permite incluirle, junto a Bernardo Germán Lorente y Pedro de Acosta, entre los más representativos creadores de trampantojos de la escuela sevillana del siglo XVIII. La producción de todos estos pintores se enmarca en una corriente cuyo origen podemos encontrar en los trabajos realizados durante el último tercio del siglo XVII por Marcos Fernández de Correa y Juan Fernández del Carpio, testimonios, en definitiva, del éxito de un género que, procedente de los Países Bajos, alcanzó en Sevilla un importante desarrollo.

Lorenzo Alonso de la Sierra Fernández

\section{DOS RETRATOS DE SAN JEROTEO Y SAN DIONISIO AREOPAGITA DE JOSÉ DE CIEZA EN EL MUSEO EPISCOPAL Y CAPITULAR DE HUESCA}

La limpieza de dos óleos conocidos como retratos de Copérnico y Galileo del Museo Episcopal y Capitular de Huesca (Figs. 1-3), procedentes de la antesacristía de la propia Catedral, para la segunda parte de la exposición Signos ${ }^{1}$, ha permitido leer en ellos la fima del pintor granadino José de Cieza (1656-1692), que según Palomino comenzó a destacar en Granada especializándose en paisajes y flores al temple y en las decoraciones para el Corpus. Afincado en Madrid en 1686, trabajó en las «mutaciones del Coliseo del Buen Retiro» ${ }^{2}$, lo que le valió el título de pintor regio con el que firma las telas oscenses. En pintura al óleo, en su etapa madrileña, Palomino cita dos de la vida de San Francisco de Paula para el convento de la Victoria, que pasaron al Museo de la Trinidad, de los que sólo se conserva uno en mal estado en el Museo del Prado ${ }^{3}$, y «muchos» que pintó para la iglesia nueva de las Mercedarias Descalzas del barrio del Barquillo (Góngoras).

Anteriores atribuciones de los lienzos del Museo Episcopal de Huesca, y un comentario al motivo representado, dando por buena la tradicional identificación, pueden verse en las fichas de la exposición Signos, firmadas por Arturo Ansón Navarro ${ }^{4}$.

En el primero, el presunto Copérnico (Figs. 1-2), vemos a un varón, de medio cuerpo, sentado a una mesa en la que aparecen un reloj de arena y varios libros-ninguno astrológico-y que, con los quevedos en la mano, interrumpe la lectura para dirigir el rostro al cielo con gesto místico. Completa la sobria decoración del estudio una ventana abierta a un celaje oscuro con una figurilla fingiendo bronce en el alféizar, representación de la Justicia o, según Ansón, de Astrea, pues ambas se pueden asociar astronómicamente (en el signo Libra).

En la parroquia de San Antonio de Cádiz se conserva un lienzo que representa la Oración en el Huerto, firmado por Antonio Gallardo en 1720, cuyo autor pudo guardar con él algún grado de parentesco con Francisco. Véase Enrile, J. N.: Paseo Histórico-Artístico por Cádiz, Cádiz, 1843, pp. 49-50.

\footnotetext{
I Signos. Arte y cultura en Huesca. De Forment a Lastanosa. Siglos XVI-XVII. Huesca, 1994. La restauración ha corrido a cargo de Cristina Larsen.

2 A. Palomino de Castro y Velasco. El Museo Pictórico y escala óptica III, El Parnaso español pintoresco laureado, Madrid, Aguilar, 1988, pp. 467-468.

${ }_{3}^{3}$ Inventario General de Pinturas, Museo del Prado (1992), t. II (El Museo de la Trinidad, n. ${ }^{\circ} 305$ ). El cuadro lo cita Palomino, con otro en que el santo reprocha al rey de Nápoles las riquezas que le ofrece, que son «sangre de pobres»; pasó también al Museo de la Trinidad desde el convento de la Victoria de Madrid y resultó destruido en el incendio del Tribunal Supremo de 1915. Según los antiguos inventarios iba firmado Ziezar.

${ }^{4}$ Op. cit., pp. 302-304.
} 